I heard that on Sunday, June 9 th, she was down stairs, and on the Igth I saw her. She was apparently quite well, had gained flesh; and appetite good. On examination, I found all trace of the tumour gone. The cicatrix of the incision, and a slight puckering of the skin, from which she said a little watery discharge occasionally oozed, was all that remained. The gangrenous gut had, in truth, sloughed away; the artificial anus had all but closed; and thus a thoroughly radical cure had been accomplished. A truss, with a folded napkin underneath was all she wore, and she was enabled to get about, relieved of the extra burden of her irreducible hernia.

\section{ON THE}

\section{REMOVAL OF TUMOURS BY ELECTROLYSIS.*}

By JULIUS ALTHAUS, M.D., M.R.C.P.Lond., Physician to the Landon Infirmary for Epilepsy and Paralysis.

THE object of this paper is briefly to state the results hitherto obtained by the method of starving tumours by electrolysis. Let me premise that the electrolytic treatment acts in a threefold manner, viz., first, through mechanical disintegration of the tissues by the nascent hydrogen second, through chemical destruction by free alkalies-potash, soda, and lime, which are evolved at the negative pole of the battery; and lastly, through a modification of nutrition, by the dynamic effects of the continuous galvanic current on the vasomotor nerves of the parts brought under its influence.

The entire number of cases I have up to the present time treated by electrolysis, amounts to fifty-eight, amongst which there were forty-seven non-malignant, and eleven of the malignant kind.

Eleven cases of nævus have been under my care. Of these seven were cured; one patient was only seen once, and not heard of again; one discontinued the treatment before any appreciable result was obtained; two are still under treatment, and so much improved as to give the best hopes of eventual complete success. In none of these eleven cases was there, at any time during the progress of the treatment, any bad symptom whatsoever; and in most cases not a drop of blood was lost. In one case, the growth was so extensive that both Mr. Paget and Sir William Fergusson, who were consulter previously to the patient coming under my care, refused to interfere with the tumour. In another case, where the nævus was seated on the lower eyelid, Mr. Dixon had been previously consulted, and advised to leave the growth alone, on account of its position, although the nævus was a source of great annoyance for the patient. Neither an awkward position, nor extreme size of a nævus, can ever be an impediment to the electrolytic treatment, which I believe to be suitable for all cases of nævus, indiscriminately.

Of bronchocele, I have had eight cases under treatment. Of these, two were cured, one was improved, five are still under treatment and progressing favourably. In several of these cases, Mr. Prescott Hewett, Mr. Paget, and Sir William Fergusson, had been previously consulted, and had pronounced any of the ordinary operations to be inadmissible. Most of these cases were of an enormous size, and on that account required a long continuance of the treatment; but I believe my experience justifies me in saying that any case of bronchocele, however large, may, in course of time, be cured by electrolysis.

Of sebaceous tumours of the scalp and face, I have treated fourteen cases. Of these, thirteen were cured; the fourteenth patient was obliged to leave town before the end of the treatment, but would, from the change already caused in the tumour, have been cured by one or two more applications. In sebaceous tumours the treatment is short, as they never attain to any considerable size.

Of that hypertrophy of the skin which Mr. Wilson calls ecphyma mollusciforme, I have treated five cases. Two of these were seated on the upper eyelid, two on the cheek, and one on the back of the neck. Four of these cases were cured; the fifth was not heard of again after two applications, but from the change already caused in the tumour, I believe that it must have disappeared long ere this. $\dagger$

Of kelis, I have had one case under my care; but, as I saw the patient only once, I am unable to say whether any result has been obtained.

Of lipoma, three cases have come under my treatment. One of these is nearly cured; the other two patients discontinued the treatment before any appreciable result was obtained. One of these latter patients, a highly nervous gentleman, complained of pain and swelling of the tumour, after the application, and wrote to say that some matter was formed at one of the punctures. This is the only case where some \footnotetext{
* Read before the Surgical Section at the Annual Meeting of the British Medical
Association in Dublin, August 1867 .

+ This case is now known to have been successful
}

limited suppuration seems to have taken place in consequence of the galvanic applications.

I have cured a cyst of the lower lip, in a gentleman, aged 53 , and a ganglion on the wrist of a lady, aged 30 , by the same method.

Of glandular tumours, I have treated three cases, all of which were much improved, but none continued the treatment until the entire removal of the enlargement. Thus of forty-seven cases of non-malignant tumours, twenty-nine were cured, ten improved, and in seven cases no result was obtained, or the result unknown.

In malignant disease, of which I have treated eleven cases, the results of the process are, as might have been expected, far less favourable. Wherever the cancer is one of considerable size, and growing rapidly, the pain may be relieved, and the further growth of the tumour be considerably checked by the electrolytic treatment; but $I$ have not hitherto obtained a cure of such patients. In two cases of scirrhus of the breast, where the constitution was apparently not suffering, and where the tumour was only of the size, in one of a filbert, and in the other of a nutmeg, the swelling has entirely disappeared; although, of course, I am not prepared to say that a cure has been effected. For the healing of an open cancer, the treatment seems to answer very well; I must say, however, that in no case of malignant disease have I ever trusted to electrolysis alone, but have prescribed at the same time powerful remedies to be taken internally, for modifying the constitution of the patient, such as bromide of potassium, belladonna, and quinine. Perhaps in course of time a more continuous application of the electrolytic process may be discovered, by means of which we may be able to starve out even malignant tumours with more success than has hitherto been obtained.

The only part of the electrolytic operation which is at all unpleasant to the patient, is the introduction of the needles through the skin. I, therefore, always use the ether spray, unless the patient himself objects to it. To some patients the smarting of the ether is more unpleasant than the prick of the needles, but in the majority of cases, the ether spray is preferred. The galvanism itself is almost, or even entirely painless, if judiciously applied. The length of the application should vary according to the nature of the case. For small tumours two or three minutes are frequently sufficient; for large ones fifteen to thirty minutes are preferable. In the latter, the best plan is to apply the current every day for some time; but I have also obtained satisfactory results where it was only done twice or three times a week. The instrument which I have found most useful for large tumours, is the serres-fines conductor, made for me by Messrs. Weiss. With this, from 2 to 6 needles may be introduced singly into the depth of the tumour; their heads are then grasped by the serres-fnes, which are connected with the negative pole of the battery by means of ramified conducting-wires.

The safety of the treatment, which is its chief characteristic feature, seems to me in a great measure due to the fact of its belonging to the domain of subcutaneous surgery; for although there is a slight action on the skin, yet by far the greatest effect is produced in the substance of the tumour, owing to the superior electric conductivity of the soft and warm internal structures. Pyæmia and other much-feared consequences of surgical operations, therefore, do not follow the electrolytic applications. Add to this the painless nature of the proceeding, the absence of shock and of hæmorrhage, the fact that, during the whole progress of the treatment, the patient may follow his avocations just as usual; and I hope it will be acknowledged that this method bids fair to effect a substantial improvement in surgical therapeutics.

\section{ON THE TREATMENT OF TUMOURS BY ELECTRICITY.}

BY MAURICE H. COLLIS, M.D.DUB., F.R.C.S.I., Surgeon to the Meath Hospital and co. Dublin Infirmary, etc.

THERE are three distinct methods in which electricity, in its various forms, may be employed by the surgeon: 1 , as a cautery; 2 , as an agent for chemical decomposition ; 3 , as a nerve-stimulant. It is, no doubt, a question whether the first and second forms differ merely in degree; but, as I do not propose to deal with them in the present paper, I shall not enter upon the question. The application of electricity for the chemical decomposition of tumours has found an able exponent in Dr. Julius Althaus. The ordinary uses of electricity in the third form are limited generally to cases of muscular paralysis or muscular atrophy. The induced and interrupted current gives the best results in the former; the continued galvanic current in the latter.

Early in the present century, when galvanism was still new, it was

- Read before the Surgical Section at the Annual Meeting of the British Medical Association in Dublin; August $\mathbf{8 6 7}$. 
applied to many things, with a sanguine hope of its proving a valuable curative agent. Partly from ignorance of its nature, partly from want of experience as to its varying powers, and partly from impatience of the consequent failures, it was soon cast aside, and has been ever since, as I think, too much neglected. Its beneficial action in cases of paralysis and atrophy ought to have taught us that we possess in it an agent of great power; and the vast advances in our knowledge of its various forms and modes of action as a chemical agent ought to have led us to a more extended application of its powers as a curative agent. I must acknowledge having been led to study it in this latter respect by reading Dr. Althaus's paper on its use in the chemical decomposition of tumours. I tested his experiments, and found that there was literally no limit to the decomposing power of the continuous current derived from such batteries as Daniell's. Tumours and healthy tissues could be decomposed at a great pace-not without pain, certainly, but to any ex. tent that might be desired, provided a battery of sufficient strength were employed. This mode of applying galvanism to tumours seemed to me very closely to resemble, as to its results, the action of other chemical decomposers, such as the strong caustics. Great immediate destruction of the morbid growth could, no doubt, be obtained, but a complete removal could not be promised, much less an immunity from relapse, or from extension of the growth by its periphery. Dr. Althaus's milder battery seems well adapted for some simple tumours, and I have seen good effects from it.

It occurred to me, however, that something could be done towards procuring the absorption of tumours, or perhaps towards checking their growth, by using galvanism simply as a stimulant. A slight occasional current, by its stimulus, will develope a wasted muscle; while the continuous use of the same current will, by over-stimulation, cause it again to waste. I therefore sought to apply this principle to tumours of various kinds, and to cause them to waste by keeping up a constant flow of electricity through them.

For reasons which I need not enter on, I tried various forms of battery; and finally I returned to the simple voltaic pile, composed of a dozen or more couples of zinc and copper an inch and a half square, or of small cylinders or plates of wood covered with felt, and wrapped round with zinc and copper wire. These simple batteries were excited by salt and water, or by sulphuric acid in the proportion of one to twenty parts of water.

The mode of application was as follows. The tumour was covered with a plate of zinc, perforated zinc, silver foil, copper, or copper plated with silver. The positive pole was connected with this plate; the negative pole with a plate of copper, which was brought into contact with the skin of the back or other convenient part. The battery, tied up in gutta-percha paper, or oiled silk, lay on a table, or was tied round the waist of the patient.

The results were as follows.

r. Complete removal of secondary cancerous deposit from a gland in the neck.

2. Rapid absorption of inflammatory deposit over and round an im. mense mass of strumous gland.

3. Slow removal of said gland.

4. Immediate check to the growth of a tumour composed of an aggregation of strumous glands.

5. Considerable cutaneous and subcutaneous inflammation in the same case, with softening and breaking up of the diseased glands.

6. Decided absorption of inflammatory effusions round primary scirrhus of mammary region.

7. Diminution and softening of a very firm fibrous growth attached to the periosteum.

All these results, except No. 3 , were obtained in from three to six days; and all the cases had previously been submitted to a variety of treatment without benefit. Special results of a peculiar nature were observed as follows.

8. The zinc plate on the skin shewed the usual tendency to decompose the skin and produce ulcerations in a few hours.

9. Perforated zinc, employed to obviate this, produced phlyctenæ and pustules in the interspaces not covered by it.

10. Silver, whether as foil or plated on copper, produced redness of the skin, but with less rapid tendency to ulceration.

II. Copper plates were comparatively slow to act on skin in connexion with the negative pole; but the copper connected with the positive pole on one occasion blistered the skin severely when a very strong battery was used.

For the rest, the batteries of wire coiled on wood are much the lighter and more convenient in proportion to their strength. They preserve their activity sufficiently, and do not wear out so soon as the voltaic pile of zinc and copper plates. They have the further advantage, that as many or as few as are desired can be used without delay in arrangement. I believe that a very strong current, whether as to qxantity or tension, is not required. A small quantity is sufficient to excite the nerves of the blood-vessels; and there should be just sufficient tension to ensure that the current pass through the part to be acted on, and not merely round by the skin. I believe that, without claiming any miraculous power for electricity thus applied, we have in it an agent of considerable energy, and capable of yielding results of sufficient value to warrant us in resorting to it more frequently than hitherto.

\section{REPORTS}

\section{OF}

MEDICAL AND SURGICAL PRACTICE IN THE HOSPITALS OF GREAT BRITAIN.

\author{
KING'S COLLEGE HOSPITAL.
}

LARGE BONY TUMOUR OF THE FACE: OPERATION: DEATH. (Under the care of SIR WILLIAM FERGUSSON.)

WE gave details of this interesting case among our Hospital Report November 23rd, to which we refer our readers. We now append a description of the operation performed on Saturday last, with the remarks made at the time by Sir William Fergusson.

The patient having been put well under chloroform, Sir William commenced by making an incision in the middle line of the upper lip, continuing it upwards and outwards round the left ala of the nose to the inner angle of the orbit. A second incision was then made from this point outwards to within half an inch of the ear. The flap was then dissected back, and reflected outwards by means of Hey's saw and Sir William's lion forceps, which he devised for a similar operation. The whole mass of bone was with little difficulty removed. The actual cautery was then applied, and the wound closed, a piece of sponge being introduced to support the parts.

Sir William, in his remarks after the operation, stated that the method which he had adopted was one the value of which he had some years past brought before the notice of the profession. The old operation consisted in removing all the bony structures, from the palate to the floor of the orbit inclusive; and this was adopted from a false view of the pathology of these growths. He remarked that many of the socalled tumours of the antrum were really tumours of the neighbouring parts, pushing their way into the antrum, and not originating in the walls of that cavity. In most of these cases, as in the present one, the alveolar processes have been found to be intact; and he has long deemed it quite unnecessary to remove them, which practice he followed ant in the present instance. By this means, the teeth are left opposed to those of the lower jaw, and the amount of deformity is considerably diminished.

The patient recovered from the effects of the chloroform, and, with the exception of a chemosis of the conjunctiva, which was punctuved on December Ist, he progressed most favourably, sleeping well, and his appetite remaining good. Early on Tuesday morning, Mr. Willcos, the house-surgeon, was called to see him, and found that his respira. tion had become quick and shallow and his pulse very rapid and weak. Stimulants, in large quantities, were given him; but he gradually sank, and died a couple of hours after.

At the post mortem examination, there was found pneumonic consolidation of the bases of both lungs. A large, very firm, fibrinous clat was found in the right ventricle, and extending into the pulmonary artery for some little distance. At the base of the brain, the remains of the tumour was found to involve the body of the sphenoid bone, chiefly on the left side. There was a small nodule, about the size of a filbertnut, pressing slightly on the optic nerve at its entrance to the optic foremen. The organs were otherwise healthy.

\section{ST. BARTHOLOMEW'S HOSPITAL.}

FRACTURE OF THE SKULL: EPILEPTIFORM CONVULSIONS: RECOVERY.

(Under the care of Mr. PAger.)

F. D., aged 38 , was brought into the hospital on November $4^{\text {th, said to }}$ have fallen a quarter of an hour before from a height of twelve feet upon his head, striking it on the kerbstone. He had had a good deal of beer to drink, but was by no means intoxicated. Mr. Square, the HouseSurgeon, who kindly gave us the notes of this and the following case, 